\title{
Electrocatalytic Hydrogen Evolution by an Iron Complex Containing a Nitro-Functionalized Polypyridyl Ligand
} Carolyn L. Hartley, Ryan J. DiRisio, Trevor Y. Chang, Wanji Zhang, and William R. McNamara*

Department of Chemistry, College of William and Mary, 540 Landrum Drive, Williamsburg VA 23185

\begin{abstract}
Iron polypyridyl complexes have recently been reported to electrocatalytically reduce protons to hydrogen gas at $-1.57 \mathrm{~V} v \mathrm{vs}$. $\mathrm{Fc}^{+} / \mathrm{Fc}$. A new iron catalyst with a nitrofunctionalized polypyridyl ligand has been synthesized and found to be active for proton reduction. Interestingly, catalysis occurs at $-1.18 \mathrm{~V} \mathrm{vs.} \mathrm{Fc}^{+} / \mathrm{Fc}$ for the nitro-functionalized complex, resulting in an overpotential of $300 \mathrm{mV}$. Additionally, the complex is active with a turnover frequency of $550 \mathrm{~s}^{-1}$. Catalysis is also observed in the presence of water with a $12 \%$ enhancement in activity.
\end{abstract}

\section{Introduction}

One of the great challenges facing the current generation of scientists involves limiting our dependence on fossil fuels. In order to relieve pressure on dwindling fossil fuel reserves, renewable energy must be pursued. Solar energy appears to be a viable long-term source of energy because roughly 400 times the amount of energy needed each year strikes the earth as harvestable solar energy. ${ }^{1}$ One method of utilizing solar energy involves the development of systems for artificial photosynthesis (AP). In general, these systems are designed to use solar energy to photochemically split water, converting sunlight into both electricity and fuel in the form of $\mathrm{H}_{2}{ }^{2}$ Although noble metals can be used to reduce protons to hydrogen gas, the rare nature of these materials limits their widespread use in devices for AP. Therefore, it is critical to develop complexes containing earth-abundant metals that can catalytically reduce protons to hydrogen gas.

Many cobalt glyoxime complexes have been studied and can be tuned to operate at low overpotential. ${ }^{3}$ Other cobalt and nickel complexes have been discovered that are remarkably active with turnover frequencies (TOFs) as high as $10^{5} \mathrm{~s}^{-1} .{ }^{4}$ However, many of the cobalt and nickel catalysts are unstable and operate in only organic solutions. To circumvent this limitation, polypyridyl ligands have been coordinated to cobalt and molybdenum, resulting in highly stable catalysts that can generate hydrogen from aqueous solutions. ${ }^{5}$ Although there are many examples of active cobalt, nickel, and molybdenum complexes, there are far fewer examples of molecular iron catalysts that generate hydrogen in the presence of water.

One approach to developing active iron catalysts involves mimicking the active site of hydrogenase enzymes. ${ }^{6}$ Functional mimics that are active electrocatalysts for hydrogen generation often operate at potentials that are more cathodic than $-1.6 \mathrm{~V} \mathrm{vs.} \mathrm{Fc}^{+} / \mathrm{Fc}^{6}$ Additionally, these catalysts are significantly less active than $[\mathrm{Fe}] \mathrm{H}_{2}$ ase. ${ }^{7,8}$ In an effort to develop a water-stable iron catalyst, we have recently reported a mononuclear iron polypyridyl catalyst (Figure 1) that is active in aqueous solutions. ${ }^{9}$ Although the iron polypyridyl catalysts are active and stable, catalysis occurs at $-1.57 \mathrm{~V} \mathrm{vs}$. $\mathrm{Fc}^{+} / \mathrm{Fc}$, corresponding to an overpotential of

*Corresponding author. Tel.: 757-221-4868; fax: 757-221-2715.

Email: wrmcnamara@wm.edu 
$800 \mathrm{mV}$. We reasoned that functionalizing the ligand with an electron withdrawing group would result in an iron catalyst that operates at a significantly less cathodic potential.

Herein we report the synthesis and characterization of an iron complex (2) containing a nitro-functionalized polypyridyl ligand and its corresponding electrocatalytic activity. The incorporation of an electron withdrawing nitro group on the phenolate ring of the complex results in a catalyst that reduces protons at $-1.18 \mathrm{~V} \mathrm{vs.} \mathrm{Fc}^{+} / \mathrm{Fc}$, corresponding to an overpotential of just $300 \mathrm{mV}$. This represents a significant improvement over complex $\mathbf{1}$ and is a promising step towards developing an iron catalyst that is stable, active, and operates at low overpotential.

\section{Materials and Methods}

\section{Materials and Methods}

2-hydroxy-5-nitrobenzaldehyde was purchased from Alfa Aesar. Bis(pyridin-2-ylmethyl)amine was purchased from Aldrich. Iron (III) chloride and potassium hydroxide were purchased from Fisher Scientific. Tetra-n-butylammoniumhexafluorophosphate (98\%), was purchased from Acros Organics. All other reagents were purchased from Fisher Scientific and used without further purification.

\section{Syntheses}

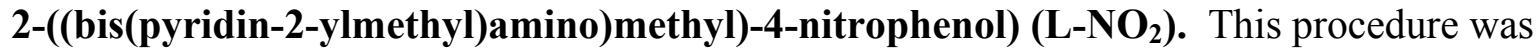
modified from a literature method. ${ }^{10}$ 2-hydroxy-5-nitrobenzaldehyde (500 mg, $3 \mathrm{mmol}$ ) was dissolved in $50 \mathrm{~mL}$ of methanol and degassed with argon. A degassed solution of bis(pyridin-2ylmethyl)amine $(0.54 \mathrm{~mL}, 3 \mathrm{mmol})$ in $5 \mathrm{~mL}$ of methanol was transferred to the aldehyde solution using a cannula. Glacial acetic acid was added ( 3 drops) followed by the dropwise addition of an air-free solution of sodium cyanoborohydride $(190 \mathrm{mg}, 3 \mathrm{mmol})$ in $5 \mathrm{~mL}$ methanol. The resulting clear, red solution was refluxed for 1 hour and then stirred for 24 hours at room temperature. 1 $\mathrm{M} \mathrm{HCl}$ was added to the solution until it reached $\mathrm{pH}=4$. The solution was evaporated to dryness and dissolved in $25 \mathrm{~mL}$ of saturated $\mathrm{Na}_{2} \mathrm{CO}_{3}$ solution and extracted with chloroform. The organic layers were combined, dried with $\mathrm{Na}_{2} \mathrm{SO}_{4}$, and filtered through celite. The solvents were removed under vacuum to yield a red oil. The ligand was then purified using silica gel chromatography with 9:1 dichloromethane:methanol. The desired compound eluted first and the solvent was removed under vacuum to give $540 \mathrm{mg}$ of the purified product $(1.85 \mathrm{mmol}, 62 \%$ yield). ${ }^{1} \mathrm{H}$ NMR $\left(\mathrm{CDCl}_{3}\right): \delta 8.58(\mathrm{~d}, 2 \mathrm{H}), \delta 8.12(\mathrm{~d}, 1 \mathrm{H}), \delta 8.05(2,1 \mathrm{H}), \delta 7.66(\mathrm{t}, 2 \mathrm{H}), \delta 7.30(\mathrm{~d}$, $2 \mathrm{H}), \delta 7.21(\mathrm{t}, 2 \mathrm{H}), \delta 6.95(\mathrm{~d}, 1 \mathrm{H}), \delta 3.93(\mathrm{~s}, 4 \mathrm{H}), \delta 3.85(\mathrm{~s}, 2 \mathrm{H}) .{ }^{13} \mathrm{C} \mathrm{NMR}\left(\mathrm{CDCl}_{3}\right): \delta 164.27, \delta$ $157.71, \delta 148.69, \delta 139.68, \delta 137.06, \delta 126.54, \delta 125.61, \delta 123.52, \delta 123.08, \delta 122.41, \delta 117.17$, $\delta 58.67, \delta 56.10 . \mathrm{m} / \mathrm{z}$ for $\mathrm{C}_{19} \mathrm{H}_{18} \mathrm{~N}_{4} \mathrm{O}_{3} \mathrm{H}^{+}$expected $=351.15$, found $=351.15$.

$\left[\mathrm{FeCl}_{\mathbf{2}}\left(\mathbf{L}_{\mathbf{N}} \mathrm{NO}_{2}\right)\right]$ (2). The complex was synthesized using a modified literature procedure. ${ }^{9} \mathbf{L}-$ $\mathbf{N O}_{2}(100 \mathrm{mg}, 0.6 \mathrm{mmol})$ and triethylamine $(83 \mu \mathrm{L}, 0.6 \mathrm{mmol})$ were dissolved in $10 \mathrm{~mL}$ of

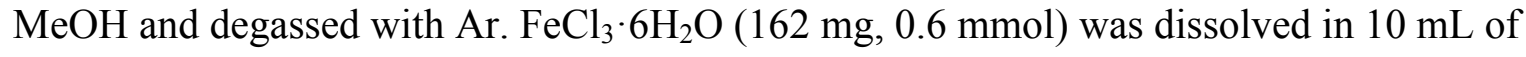


methanol and degassed with argon. The ligand solution was transferred to the flask containing the iron precursor using a cannula. The solution immediately turned deep purple with a visible precipitate. The reaction was stirred at room temperature for 1 hour and was filtered. The filtrate was evaporated to dryness and was washed with cold methanol to give the product as a purple solid (118 mg, 41\% yield). Crystals suitable for X-ray diffraction were grown by diffusion of diethyl ether into a solution of 2 in dichloromethane. $\mathrm{M} / \mathrm{z}$ for $\mathrm{C}_{19} \mathrm{H}_{17} \mathrm{Cl}_{2} \mathrm{FeN}_{4} \mathrm{O}_{3} \mathrm{Na}^{+}$ expected $=497.991934$, found $=497.992060$. Anal'd calc'd for $2: \mathrm{C}, 47.83 ; \mathrm{H}, 3.80 ; \mathrm{N}, 11.74$. Found: C, 47.77, H, 3.83, N, 11.90

\section{Instrumentation}

${ }^{1} \mathrm{H}$ and ${ }^{13} \mathrm{C}$ NMRs were performed on an Agilent 400MR DD2 instrument operating in pulse Fourier transform mode. Chemical shifts were referenced to residual solvent. Mass spectrometry was carried out using positive electrospray ionization on a Bruker 12 Tesla APEX-Qe FTICRMS with an Apollo II ion source.

X-Ray Diffractometry. A single crystal was mounted on a glass fiber and data was collected with graphite-monochromated $\mathrm{Cu} \mathrm{K} \alpha$ radiation $(\lambda=1.54187 \mathrm{~nm})$ on a Bruker-AXS three-circle diffractometer using a SMART Apex II CCD detector. The crystal structure was solved and refined using SIR2014 and SHELXL-2014/7.

Cyclic Voltammetry (CV). A CH Instruments 620D potentiostat with a CH Instruments 680 amp booster was used for all experiments. Each experiment was performed in a standard threeelectrode cell with a glassy carbon working electrode (diameter $=0.30 \mathrm{~cm}$ ), a Pt auxiliary electrode, and an SCE reference electrode. Tetrabutylammonium hexafluorophosphate $\mathrm{TBAPF}_{6}$, $0.1 \mathrm{M}$ ) was used as the electrolyte. Ferrocene was added and used as an internal reference. All electrochemical experiments were performed under an Ar atmosphere. The working and auxiliary electrodes were polished with alumina powder paste $(0.05 \mu \mathrm{m})$ on a cloth-covered polishing pad and then rinsed with water and acetonitrile before each scan (unless otherwise noted). For the acid addition experiments, trifluoroacetic acid (TFA) was added under argon.

Acid Addition Study. In an electrochemical cell, $0.5 \mathrm{mg}$ of crystals of 2 were dissolved in 5.0 $\mathrm{mL}$ of $0.1 \mathrm{M} \mathrm{TBAPF}_{6}$ in $\mathrm{CH}_{3} \mathrm{CN}$. Cyclic voltammograms (CVs) were obtained at different concentrations of TFA.

Bulk Electrolysis. Controlled-potential coulometry (CPC) experiments were conducted in a closed $500 \mathrm{~mL}$ four-neck round-bottom flask. Complex $2(0.5 \mathrm{mg})$ was added to $50 \mathrm{~mL}$ of $0.1 \mathrm{M}$ $\mathrm{TBAPF}_{6}$ with in $\mathrm{CH}_{3} \mathrm{CN}$. The flask was capped with two vitreous carbon electrodes and a silver wire reference electrode, all submerged in solution and separated by VYCOR frits. The solution was purged with argon and TFA was added resulting in a $65 \mathrm{mM}$ solution. A CPC was run at $1.2 \mathrm{~V} \mathrm{vs} . \mathrm{Fc}^{+} / \mathrm{Fc}$ for $1800 \mathrm{~s}$, resulting in a faradaic yield of $98 \%$. No hydrogen was observed when the experiment was performed without catalyst. 
Scan Rate Dependence. In an electrochemical cell, $0.5 \mathrm{mg}$ of $\mathbf{2}$ was dissolved in $5.0 \mathrm{~mL}$ of 0.1 $\mathrm{M} \mathrm{TBAPF}_{6}$ in $\mathrm{CH}_{3} \mathrm{CN}$. Cyclic voltammograms were taken at scan rates ranging from $50 \mathrm{mV} / \mathrm{s}$ to $700 \mathrm{mV} / \mathrm{s}$.

\section{Results and Discussion}

The ligand $\left(\mathbf{L}-\mathrm{NO}_{2}\right)$ was obtained through a simple condensation reaction of 2-hydroxy5-nitrobenzaldehyde with bis(pyridin-2-ylmethyl) followed by a reduction using sodium cyanoborohydride (62\% yield). The phenol group of $\mathbf{L}-\mathbf{N O}_{2}$ was deprotonated with triethylamine and the ligand was coordinated to $\mathrm{FeCl}_{3}$ in methanol. X-ray quality crystals were grown from slow diffusion of diethyl ether into a dichloromethane solution of $\mathbf{2}$.

Figure 2 shows the ORTEP diagram of $\mathbf{2}$ with hydrogen atoms omitted for clarity. The structure confirms that the ligand binds to iron to give a distorted octahedral complex. An O-Fe$\mathrm{N}$ bond angle of $163.7^{\circ}$ and an N-Fe-N bond angle of $73.9^{\circ}$ delineate from the $180^{\circ}$ and $90^{\circ}$, respectively, that are expected for typical octahedral complexes. The distorted octahedral geometry is likely a result of the 6-membered chelate ring formed from the bonding of the phenolate to the iron center. An Fe-O bond length of $1.945 \AA$ is consistent with what is typically observed for $\mathrm{Fe}^{\mathrm{III}}$-phenolate bonds. ${ }^{10}$

Table 1. Bond lengths $[\AA]$ and angles $\left[^{\circ}\right]$ for $\mathbf{2}$.

\begin{tabular}{lr}
\hline Bond Length $(\AA)$ & $1.945(5)$ \\
$\mathrm{Fe}(1)-\mathrm{O}(1)$ & $2.184(6)$ \\
$\mathrm{Fe}(1)-\mathrm{N}(2)$ & $2.186(6)$ \\
$\mathrm{Fe}(1)-\mathrm{N}(1)$ & $2.227(7)$ \\
$\mathrm{Fe}(1)-\mathrm{N}(3)$ & $2.282(2)$ \\
$\mathrm{Fe}(1)-\mathrm{Cl}(4)$ & $2.316(2)$ \\
$\mathrm{Fe}(1)-\mathrm{Cl}(3)$ & \\
& \\
$\mathrm{Bond}$ Angle ( $)$ & \\
$\mathrm{O}(1)-\mathrm{Fe}(1)-\mathrm{N}(2)$ & $82.8(2)$ \\
$\mathrm{O}(1)-\mathrm{Fe}(1)-\mathrm{N}(1)$ & $163.7(2)$ \\
$\mathrm{N}(2)-\mathrm{Fe}(1)-\mathrm{N}(1)$ & $93.2(2)$ \\
$\mathrm{O}(1)-\mathrm{Fe}(1)-\mathrm{N}(3)$ & $89.8(2)$ \\
$\mathrm{N}(2)-\mathrm{Fe}(1)-\mathrm{N}(3)$ & $76.3(2)$ \\
$\mathrm{N}(1)-\mathrm{Fe}(1)-\mathrm{N}(3)$ & $73.9(2)$ \\
\hline
\end{tabular}


Cyclic voltammograms of 2 (Figure 3, blue) reveal a reversible redox couple at $-0.45 \mathrm{~V}$ vs. $\mathrm{Fc}^{+} / \mathrm{Fc}$ corresponding to the $\mathrm{Fe}^{\mathrm{III}} / \mathrm{Fe}^{\mathrm{II}}$ redox couple of the nitro-functionalized complex. A peak separation of $72 \mathrm{mV}$ is observed under these conditions which is consistent with what is observed for the $\mathrm{Fc}^{+} / \mathrm{Fc}$ internal standard. The $\mathrm{Fe}^{\mathrm{III}} / \mathrm{Fe}^{\mathrm{II}}$ redox couple appears at a potential that is $100 \mathrm{mV}$ more positive than the corresponding redox couple for complex 1 (Figure 3, red). Therefore, we reasoned that if complex 2 were an active catalyst, it would operate at an overpotential of $\sim 100 \mathrm{mV}$ less than $\mathbf{1}$. However, upon addition of a proton source (trifluoroacetic acid) in an acetonitrile solution, a catalytic wave can be observed at $-1.18 \mathrm{~V} \mathrm{vs.} \mathrm{Fc} / \mathrm{Fc}$ (Figure 4 , left). Interestingly, the catalytic wave of 2 appears at a potential that is $400 \mathrm{mV}$ more positive than what is observed for $\mathbf{1}$ (Figure 4, right). Catalytic activity is also observed when tosic acid is used as the proton source (see supporting information).

The current associated with this irreversible reduction event grows linearly upon addition of more acid, suggesting that catalysis is second order with respect to $\left[\mathrm{H}^{+}\right]$(Figure 5). Catalysis becomes independent of scan rate at $v=10 \mathrm{~V} / \mathrm{s}$. By performing the acid addition experiment at $10 \mathrm{~V} / \mathrm{s}$, a turnover frequency can be calculated using the same method that was used to calculate TOF for 1 (see supporting information). ${ }^{9}$ Although the method used to calculate TOF represents simple pseudo-first order system, it is also used to calculate rates for more complicated systems in order to provide a point of comparison. ${ }^{4,5,9,11}$ Although less active than $\mathbf{1}$ (TOF $=1000 \mathrm{~s}^{-1}$ ), catalyst 2 is still highly active with a TOF $=550 \mathrm{~s}^{-1}$. The observed catalytic wave at $-1.18 \mathrm{~V}$ vs. $\mathrm{Fc}^{+} / \mathrm{Fc}$ corresponds to an overpotential of just $300 \mathrm{mV}$ compared to $800 \mathrm{mV}$ reported for $\mathbf{1}$ (see supporting information) under similar experimental conditions. Additionally, the activity and overpotential for $\mathbf{2}$ are comparable with recently reported fluorinated diglyoxime-iron complexes that operate with an overpotential of $300 \mathrm{mV}$ and a TOF $\sim 200 \mathrm{~s}^{-1} .^{7 \mathrm{~b}}$

Furthermore, when aliquots of catalyst are added to a fixed amount of TFA, the catalytic wave is still observed at $-1.0 \mathrm{~V}$. When more catalyst is introduced, the current enhancement increases linearly with [2] (Figure 6), suggesting that the catalysis is first order with respect to [2]. This relationship gives rise to an overall rate expression of rate $=k[2]\left[\mathrm{H}^{+}\right]^{2}$. These observations are consistent with what was observed for the previously reported iron polypyridyl complexes. $^{9}$

From a mechanistic standpoint, complex 2 appears to behave similarly to $\mathbf{1}$. Prior to acid addition, a redox couple is observed for $\mathrm{Fe}^{\mathrm{III}} / \mathrm{Fe}^{\mathrm{II}}$ at $-0.45 \mathrm{~V}$ vs. $\mathrm{Fc}^{+} / \mathrm{Fc}$. Upon addition of acid, this redox event shifts to $-0.3 \mathrm{~V}$. This shift indicates that the first step of the catalytic cycle involves protonation of the phenol to give $\left[\mathrm{Fe}(\mathrm{L}-\mathrm{H}) \mathrm{Cl}_{2}\right]^{+}$, where $\mathrm{L}$ is the polypyridyl monophenolate ligand. This protonation is followed by the reduction of $\left[\mathrm{Fe}(\mathrm{L}-\mathrm{H}) \mathrm{Cl}_{2}\right]^{+}$to give $\left[\mathrm{Fe}(\mathrm{L}-\mathrm{H}) \mathrm{Cl}_{2}\right]$. Subsequent steps involve further reduction and protonation events resulting in a CEEC or CECE mechanism. The protonated form of both $\mathbf{1}$ and $\mathbf{2}$ are reduced at the same potential $\left(-0.3 \mathrm{~V}\right.$ vs. $\left.\mathrm{Fc}^{+} / \mathrm{Fc}\right)$, suggesting that the presence of the nitro group does not influence the reduction of $\left[\mathrm{Fe}(\mathrm{L}-\mathrm{H}) \mathrm{Cl}_{2}\right]^{+}$to $\left[\mathrm{Fe}(\mathrm{L}-\mathrm{H}) \mathrm{Cl}_{2}\right]$. This implies that upon protonation, the phenol group becomes hemilabile. Since the catalytic wave for $\mathbf{2}$ is $400 \mathrm{mV}$ more positive than what is observed for 1, complex $\mathbf{2}$ appears to benefit from the electron withdrawing effects of the nitro 
substituent. This suggests that the phenol of 2 likely re-coordinates during the later stages of catalysis.

Although 2 is active for hydrogen generation at a low overpotential compared to other iron catalysts in acetonitrile, it is of great interest to develop a system that can reduce protons in aqueous solutions. To this end, we have examined the activity of the complex in the presence of water. Figure 7 shows CVs of a solution of 2 with $8.8 \mathrm{mM}$ TFA in dry acetonitrile, and after the addition of $100 \mu \mathrm{L}(1.1 \mathrm{M})$ of water. In the presence of water, the complex sees a $12 \%$ increase in catalytic activity. Addition of more water shows that activity continues to increase until the catalysts starts to precipitate out of solution after $400 \mu \mathrm{L}$ of water is added (see supporting information). Therefore, the complex is stable and active in water, but solubility limits the application of $\mathbf{2}$ in purely aqueous solutions.

\section{Conclusions}

Previously reported iron polypyridyl monophenolate complexes have been found to be highly active and stable catalysts for proton reduction, but are limited by high overpotentials. We have found that functionalizing the phenol group of a polypyridyl monophenolate iron complex results in a catalyst that operates at a substantially lower overpotential. The catalyst is active with a TOF of $550 \mathrm{~s}^{-1}$ and operates with an overpotential of just $300 \mathrm{mV}$ (compared to $800 \mathrm{mV}$ for the previously reported iron polypyridyl complex). Catalysis is thought to proceed through a CECE or CEEC mechanism as has been reported for similar complexes. Hydrogen generation is first order with respect to [catalyst] and second order with respect to $\left[\mathrm{H}^{+}\right]$. The addition of water resulted in an increase in catalytic activity, suggesting that the complex is stable in the presence of water. The incorporation of a nitro group on the ligand has resulted in an improved catalyst and has helped to elucidate the mechanism of catalysis with this family of iron catalysts.

\section{Acknowledgements}

W.R.M. would like to thank R. D. Pike for help solving the crystal structure. This work was funded by the Research Corporation Cottrell College Science Award. Elemental analysis was obtained at the CENTC Elemental Analysis Facility at the University of Rochester, funded by NSF CHE 0650456. Mass spectrometry was carried out at the Cosmic Facility at Old Dominion University in Norfolk, VA.

\section{References}

(1) N. S. Lewis, D. G. Nocera, Powering the planet: Chemical challenges in solar energy utilization; Proc. Natl. Acad. Sci U. S. A. 2006, 103, 15729-15735.

(2) R. Eisenberg, "Rethinking Water Splitting," Science, 2009, 324, 44-45.

(3) J. L. Dempsey, B.S. Brunschwig, J. R. Winkler, H. B. Gray, Acc. Chem. Res. 2009, 42, 1995. 
(4) (a) A. D. Wilson, R. H. Newell, M. J. McNevin, J. T. Muckerman, M. Rakowski-Dubois, D. L. Dubois, J. Am. Chem. Soc. 2006, 128, 358. (b) M. Rakowski-Dubois, D. L. Dubois, Acc. Chem. Res. 2009, 42, 1974. (c) M. L. Helm, M. P. Stewart, R. M. Bullock, M. Rakowski-Dubois, D. L. Dubois, Science 2011, 333, 863. (d) W. A. Hoffert, J. A. S. Roberts, R. M. Bullock, M. L. Helm, Chem. Commun. 2013, 49, 7767-7769.

(5) (a) Y. Sun, J. P. Bigi, N. A. Piro, M. L. Tang, M, J. R. Long, C. J. Chang, J. Am. Chem. Soc. 2011, 133, 9212. (b) J. P. Bigi, T. E. Hanna, W. H. Harman, A. Chang, C. J. Chang, Chem. Commun. 2010, 46, 958. (c) Y. J. Sun, J. W. Sun, J. R. Long, P. D. Yang, C. J. Chang, C. J. Chem. Sci. 2013, 4, 118. (d) H. I. Karunadasa, C. J. Chang, J. R. Long, Nature 2010, 464, 13291333. (e) B. Stubbert, J. C. Peters, H. B. Gray, J. Am. Chem. Soc. 2011, 133, 9212. (f) W. M. Singh, M. Mirmohades, R. T. Jane, T. A. White, L. Hammarstrom, A. Thapper, R. Lomoth, S. Ott, Chem. Commun. 2013, 49, 8638.

(6) (a) E. Garcin, X. Vernede, E. C. Hatchikian, A. Volbeda, M. Frey, J. C. Fontecilla-Camps, Structure 1999, 7, 557-566. (b) J. W. Peters, W. N. Lanzilotta, B. J. Lemon, L. C. Seefeldt, Science 1998, 282, 1853-1858. (c) X. Zhao, I. P. Georgakaki, M. L. Miller, J. C. Yarbrough, M. Y. Darensbourg, J. Am. Chem. Soc. 2001, 123, 9710-9711. (d) G. A. N. Felton, R. S. Glass, D. L. Lichtenberger, D. H. Evans, Inorg. Chem. 2006, 45, 9181-9184. (e) F. Gloaguen, J. D.

Lawrence, T. B. Rauchfuss, J. Am. Chem. Soc. 2001, 123, 9476-9477.

(7) (a) M. W. W. Adams, Biochim. Biophys. Acta 1990, 1020, 115-145. (b) M. J. Rose, H. B. Gray, J. Am. Chem. Soc. 2012, 134, 8310. (c) V. Artero, M. Fontecave, Coord. Chem. Rev. 2005, 249, 1518-1535.

(8) (a) A. Le Cloirec, S. C. Davies, D. Evans, D. L. Hughes, C. J. Pickett, S. P. Best, S. Borg, Chem. Commun. 1999, 2285. (b) M. L. Singleton, J. H. Reibenspies, M. Y. Darensbourg, J. Am. Chem. Soc. 2010, 132, 8870. (c) F. Quentel, G. Passard, F. Gloaguen, Energy Environ. Sci. 2012, 5, 7757. (d) M. D. Rail, L. A. Berben, J. Am. Chem. Soc. 2011, 133, 18577-18579.

(9) G. P. Connor, K. J. Mayer, C. S. Tribble, W. R. McNamara, Inorg. Chem. 2014, 53, 54085410. (b) A. C. Cavell, C. L. Hartley, D. Liu, C. S. Tribble, W. R. McNamara, Inorg. Chem., 2015, 54, 3325-3330.

(10) R. Viswanathan, M. Palaniandava, T. Blasubramanian, P. T. Muthiah, Inorg. Chem. 1998, 37, 2943-2951.

(11) A. D. Nguyen, M. D. Rail, M. Shanmugam, J. C. Fettinger, L. A. Berben, Inorg. Chem. 2013, 52, 12847-12854. 


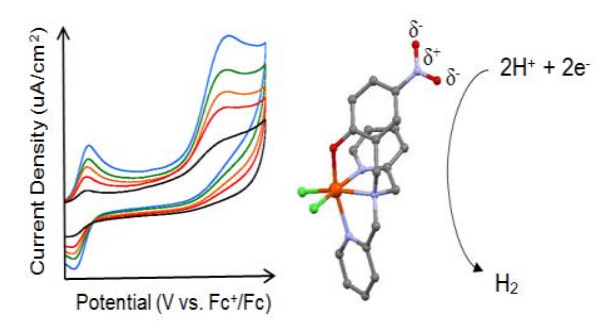

Synopsis: A new iron catalyst with a nitro-functionalized polypyridyl ligand has been synthesized and is active for proton reduction. Catalysis occurs at $-1.18 \mathrm{~V} \mathrm{vs}$. $\mathrm{Fc}^{+} / \mathrm{Fc}$ with an overpotential of only $300 \mathrm{mV}$. The complex is active with a turnover frequency of 550 $\mathrm{s}^{-1}$ and is stable in aqueous solutions. 

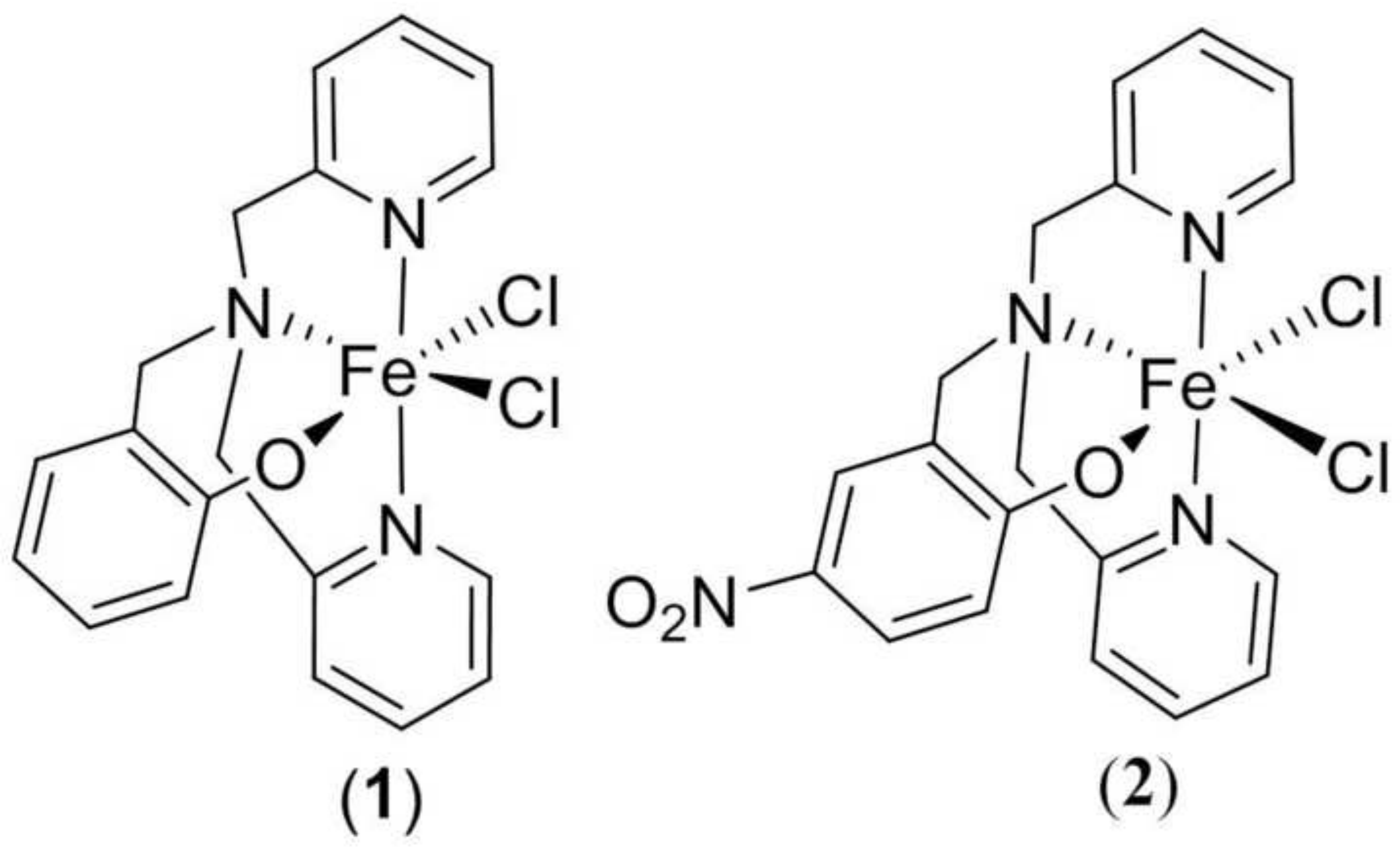


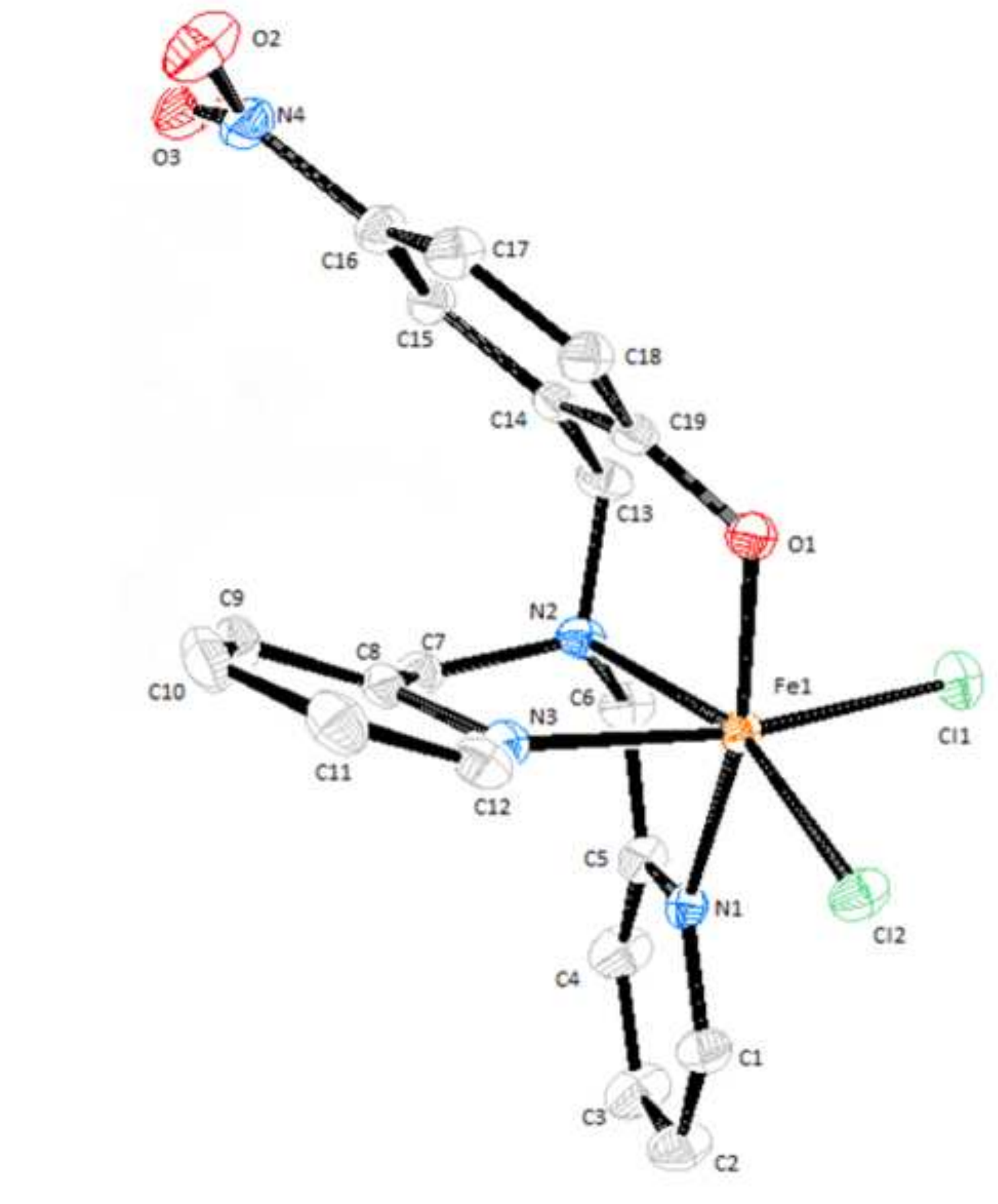

Figure 2

\section{Figure 2}
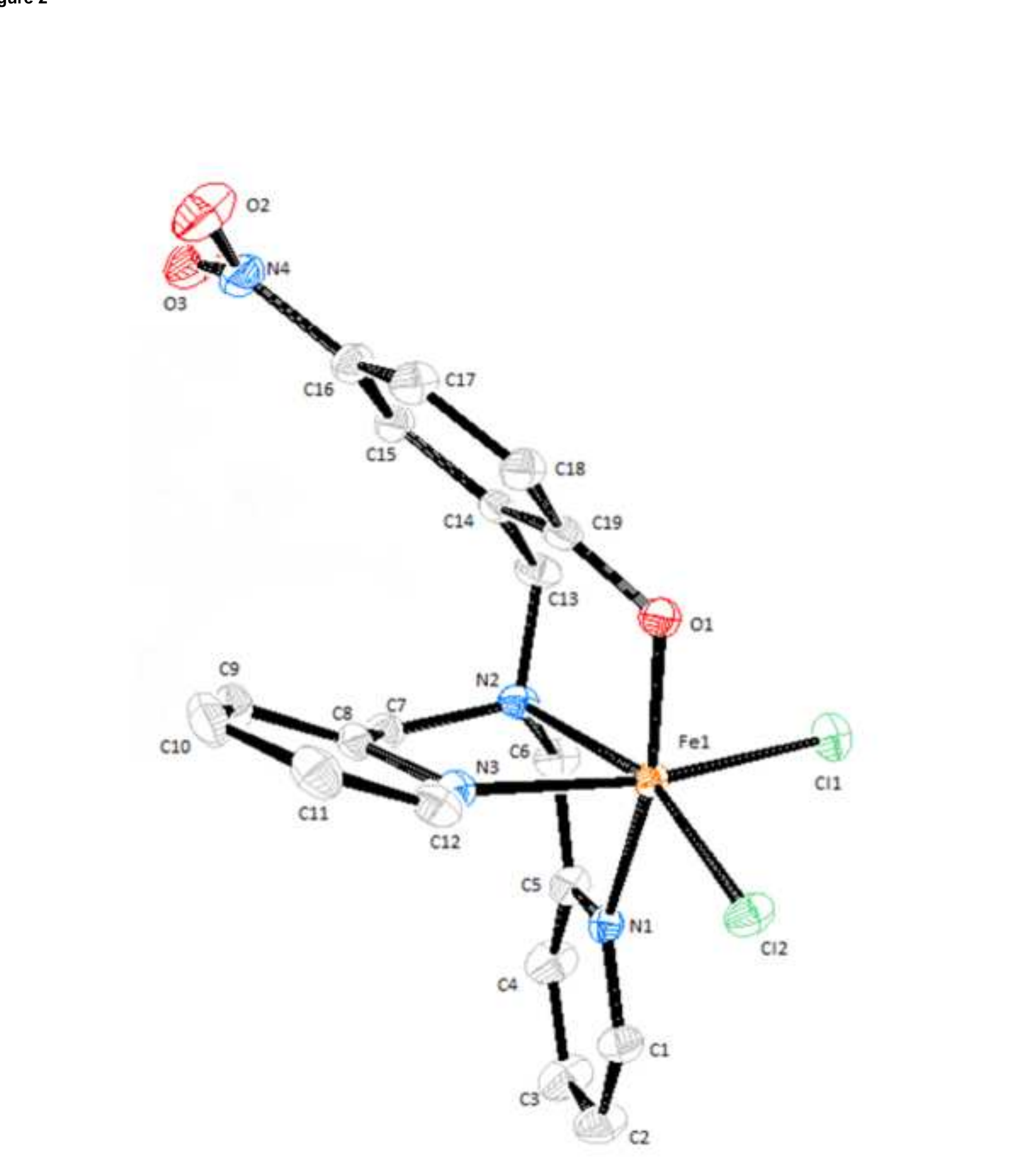


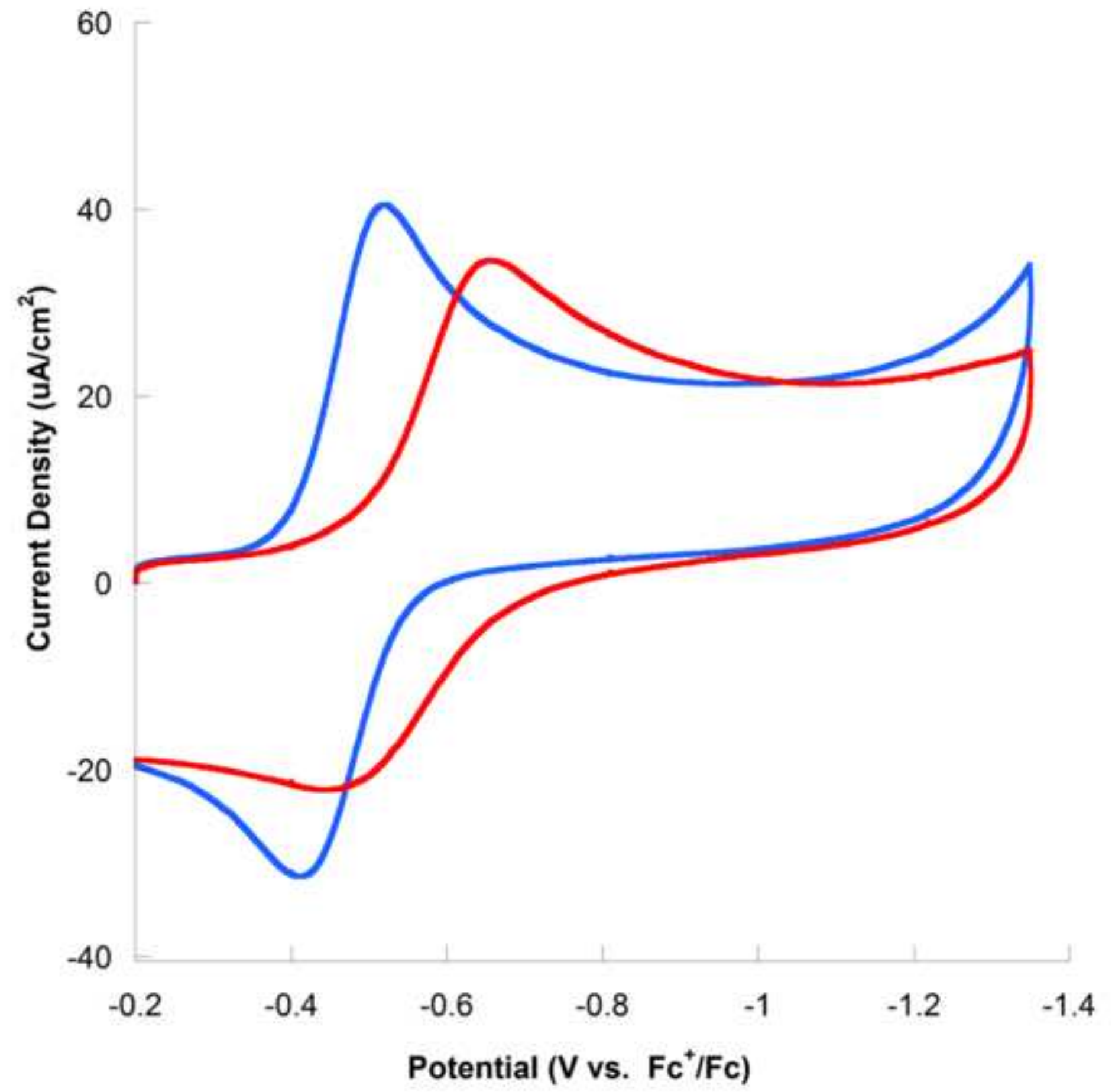



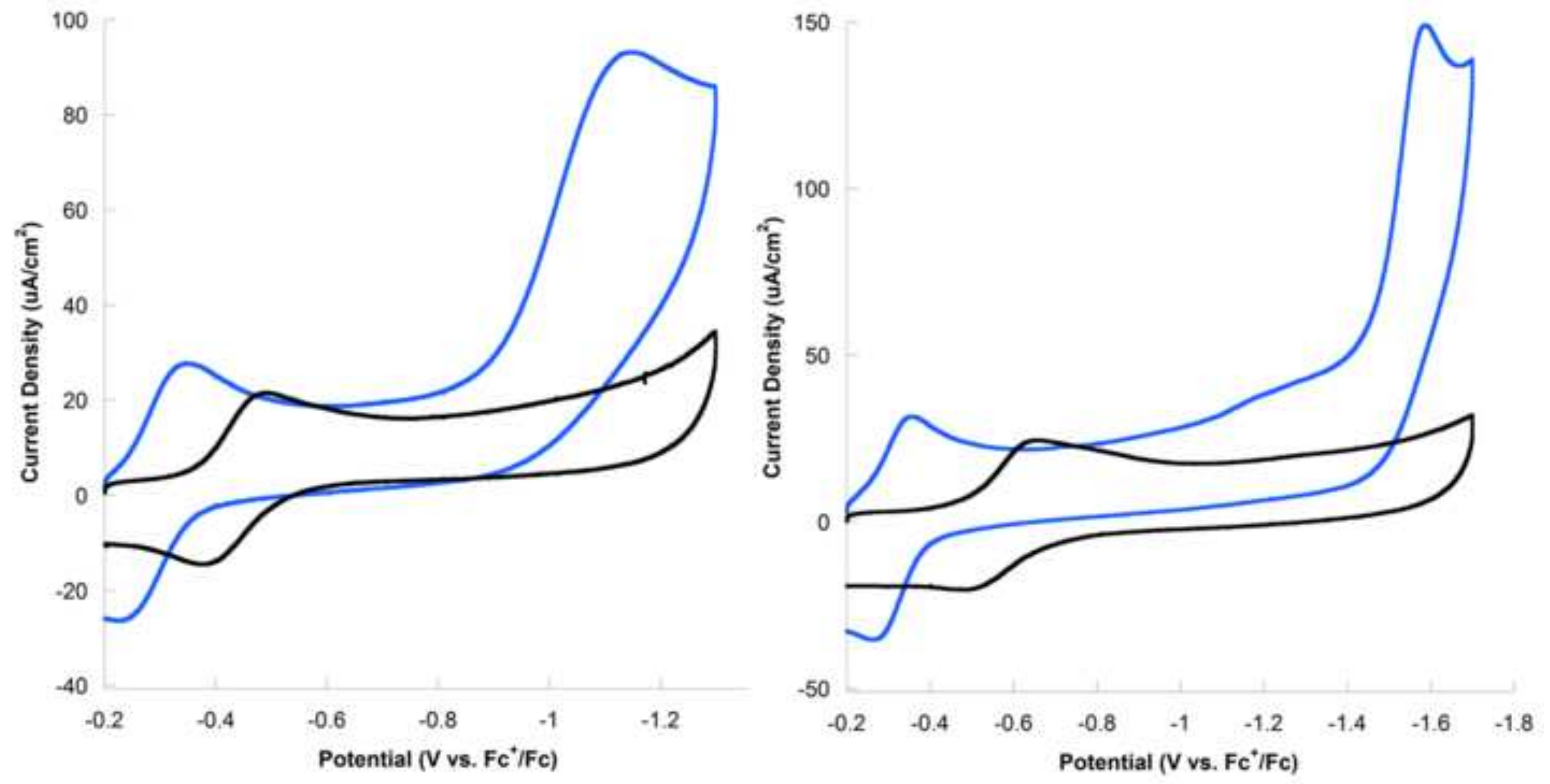
Figure 5

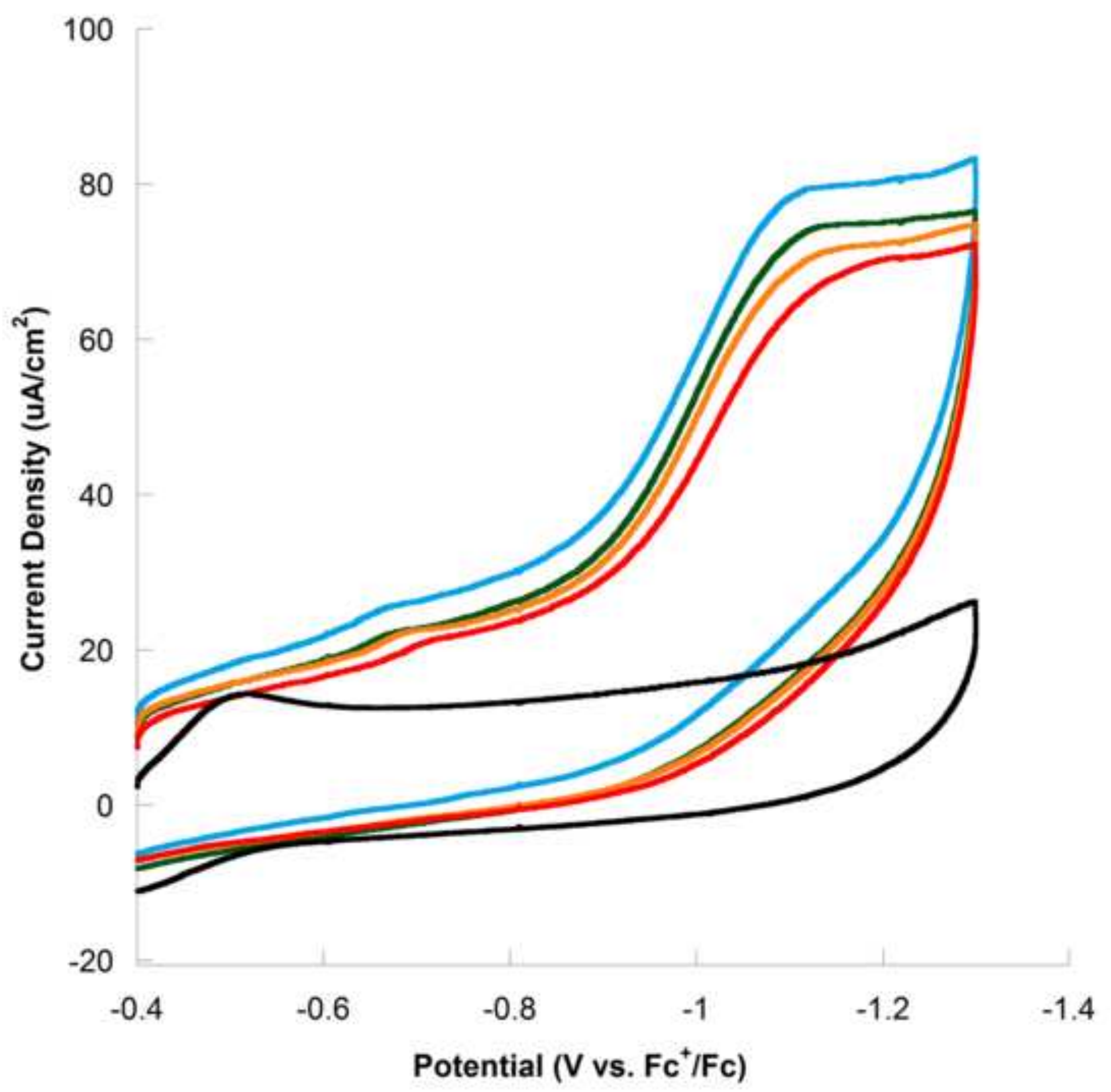




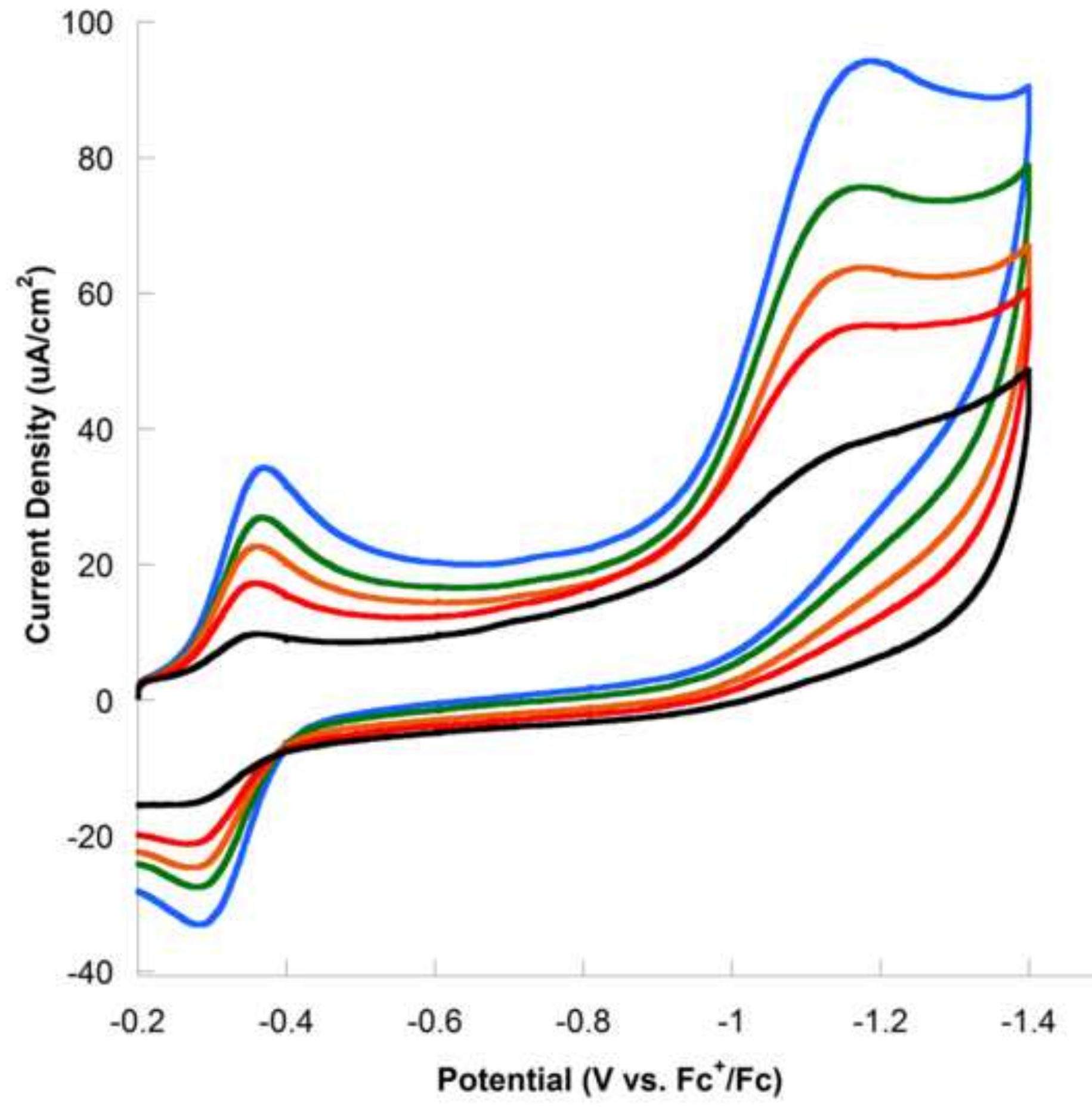




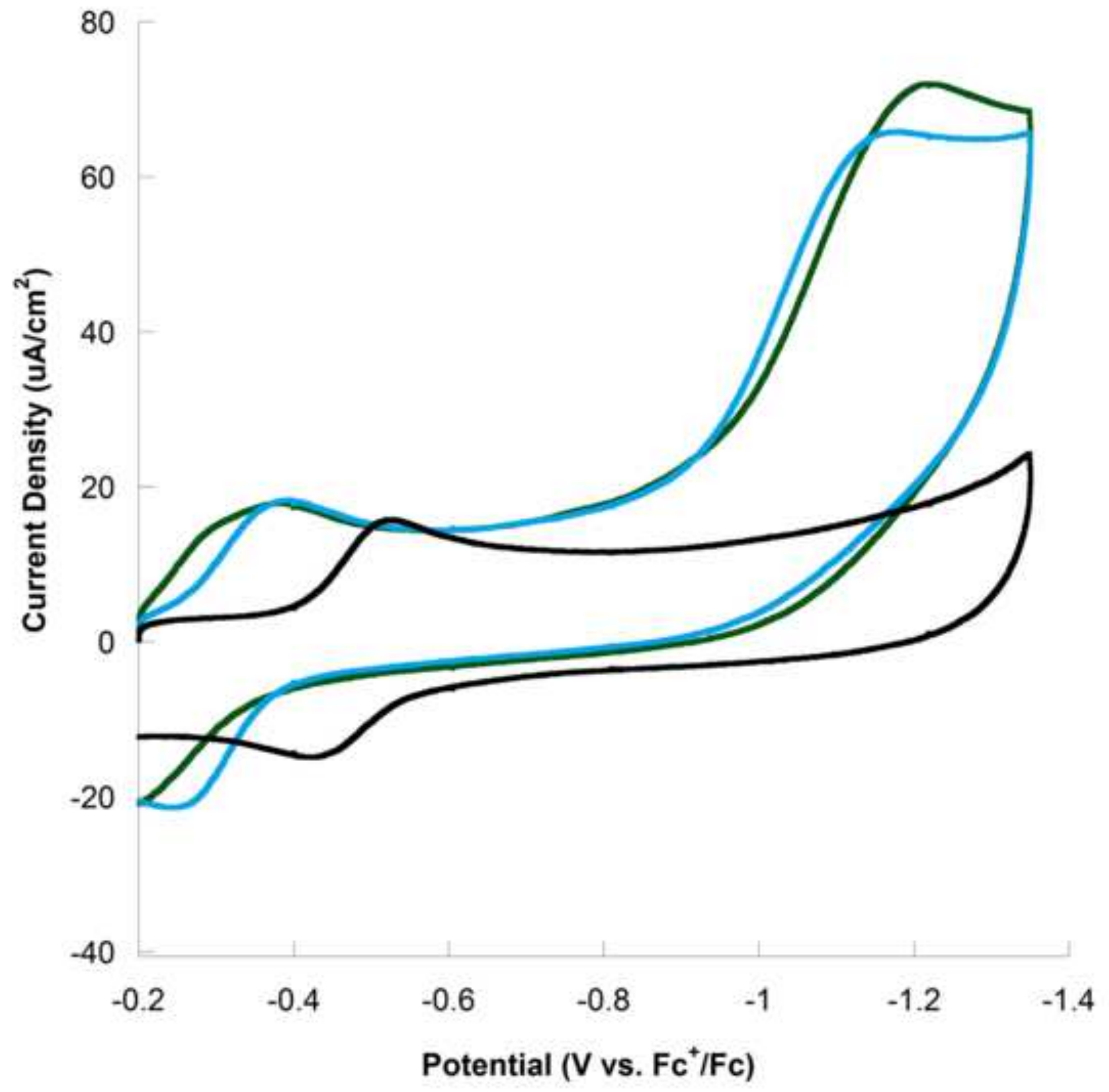

